\title{
Sympathetic Control of Lower Esophageal Sphincter Function in the Cat
}

\author{
ACTION OF DIRECT CERVICAL AND SPLANCHNIC
}

NERVE STIMULATION

\author{
Jacques Fournet, William J. SNaPe, JR., and Sidney Cohen, Gastrointestinal \\ Section of the Department of Medicine, University of Pennsylvania at the Hospital \\ of the University of Pennsylvania, Philadelphia, Pennsylvania 19104
}

\begin{abstract}
A B S TRACT The purpose of this study was to determine the effect of direct stimulation of the sympathetic nerves on the lower esophageal sphincter (LES) in the anesthetized cat. Neither unilateral nor bilateral cervical sympathectomy, or splanchnicectomy significantly modified basal LES pressure in animals with intact vagi, or animals having undergone bilateral cervical vagotomy. Electrical stimulation of the cut, peripheral, cervical sympathetic trunk increased mean arterial blood pressure, but had no effect on LES pressure or LES relaxation as induced by vagal stimulation. Stimulation of the central end of the cervical sympathetic trunk had no effect on LES pressure. Stimulation of the central end of the cut splanchnic nerve produced a decrease in LES pressure with a maximal response of $69.1 \pm 16.0 \%$ (mean \pm SEM). This inhibitory response was not modified by either propranolol or bilateral cervical vagotomy. Stimulation of the peripheral end of the cut, greater splanchnic nerve gave an increase in LES pressure with a maximal response of $38.2 \pm 7.19$ $\mathrm{mm} \mathrm{Hg}$. Guanethidine, in the presence or absence of the adrenal glands, significantly augmented this excitatory response. This response was also slightly increased by phentolamine alone at $10 \mathrm{~V}, 1 \mathrm{~Hz}$, but was not altered by propranolol. The excitatory response was completely antagonized by atropine or by trimethaphan camsylate. Stimulation of the peripheral end of the splanchnic nerve inhibited LES relaxation as induced by vagal stimulation. The results of this study suggest that: $(a)$ the LES in the cat is not affected by either central or
\end{abstract}

Dr. Fournet is supported by funds from the University of Grenoble, Grenoble, France.

Received for publication 24 July 1978 and in revised form 8 December 1978. peripheral stimulation of the cervical sympathetic trunk; $(b)$ the central portion of the splanchnic nerve carries an afferent inhibitory response to the LES through yet unknown pathways; $(c)$ the peripheral splanchnic nerve carries an atropine-sensitive excitatory response to the LES; and $(d)$ the splanchnic nerves may modulate LES relaxation as induced by vagal stimulation.

\section{INTRODUCTION}

In recent studies, the role of the vagal nerves in the control of lower esophageal sphincter (LES) ${ }^{1}$ function has been emphasized. The vagi serve a major role in the initiation of LES relaxation during swallowing (1, 2). Excitatory cholinergic pathways in the vagi have been difficult to demonstrate in the opossum, but may be present in the cat $(3,4)$. Our understanding of the influence of vagal function on the LES had developed through studies designed to inhibit or stimulate the vagi directly $(1,2)$. These studies allowed the identification of neural pathways of the nonadrenergic inhibitory or purinergic type that were not previously recognized during earlier studies, in which only agonists or antagonists were parenterally administered (5). At the present time, our understanding of the sympathetic control of LES function is based upon studies in which alpha or beta adrenergic agonists or antagonists were given $(6,7)$. Recent studies using accurate measures of LES function have not been performed with direct stimulation of the sympathetic innervation to the LES $(8,9)$.

${ }^{1}$ Abbreviation used in this paper: LES, lower esophageal sphincter. 
The purpose of this study is threefold: first, to determine the effect of direct stimulation or section of the cervical sympathetic or greater splanchnic nerves; second, to identify the neural transmitter involved in mediating these changes in LES pressure; and third, to study the interaction between the sympathetic and vagal pathways involved in the regulation of LES function.

\section{METHODS}

Studies were performed in 34 adult cats of either sex, weighing between 2.0 and $4.5 \mathrm{~kg}$. Each animal was fasted for $12-18 \mathrm{~h}$ before the manometric study and was initially anesthetized with sodium pentobarbital $(50 \mathrm{mg} / \mathrm{kg}$, i.p.) or ketamine ( 10 $\mathrm{mg} / \mathrm{kg}$ ). Intravenous anesthesia was given as needed into a catheter in the femoral vein (pentobarbital, $10 \mathrm{mg}$; or ketamine, $2.0 \mathrm{mg} / \mathrm{kg}$ ). After induction of the anesthesia, a tracheotomy was performed for assisted ventilation with a respirator. A cannula inserted into the femoral artery was filled with heparin and connected to an external transducer (Statham P231A, Statham Instruments, Inc., Oxnard, Calif.) for constant blood pressure monitoring. The rectal temperature of the animal was maintained at a constant level with a heat lamp.

The neck was explored through a midline incision. The right and left vago-sympathetic trunks were identified within the carotid sheath between the internal jugular vein and the carotid artery. The sympathetic and vagal trunks were than isolated during microscopic examination and secured with two loops of umbilical tape. The sympathetic trunk was characterized as being smaller than the cervical vagus. The sympathetic trunk had prominent ganglia and rami communicantes going to the spinal cord. Nerve identity was confirmed at postmortem examination by determining continuity with the throacic sympathetic trunk.

The abdomen was opened through a midline incision. The right or left greater splanchnic nerve was identified and isolated as it transversed the diaphragm before its entry into the celiac ganglion. The trunk was then secured with two loops of umbilical tape. Nerve identity was again confirmed at postmortem examination by identifying its proximal connection to the thoracic sympathetic trunk and its distal connection to the celiac ganglion.

Esophageal manometric studies were performed using a tube assembly consisting of three polyvinyl catheters $(1.4 \mathrm{~mm}$ inside diameter) with side orifices of similar size spaced at 5-cm intervals. Each catheter was continuously infused with distilled water at a rate of $1.2 \mathrm{ml} / \mathrm{min}$. This rate of infusion gave a $>200 \mathrm{~mm} \mathrm{Hg} / \mathrm{s}$ rise in pressure upon occlusion of the recording orifice. The intraluminal pressures were transmitted to external transducers with outputs graphed on a Beckman rectilinear ink writing recorder (Beckman Instruments, Inc., Fullerton, Calif.).

In each animal, the recording catheter was passed through the mouth into the stomach. The catheter was withdrawn while recording pressure at $0.5-\mathrm{cm}$ intervals for a $1.0-\mathrm{min}$ period. Upon completion of the pull through, the recording tube was anchored with the middle orifice in the LES at the point of maximum recorded pressure. After the pull through, the tube was secured at the jaw with tape, and within the abdomen with small arterial clips fixed at the distal esophagus and most proximal stomach. This arrangement prevented axial movement of the LES in relation to the tube orifice. This was verified using a separate tube with axial openings at $1.0-\mathrm{cm}$ intervals. The LES high pressure remained at the desired catheter opening. Also, manual orad movement of the esophagus did not displace the LES from the recording orifice.

LES pressure was recorded as millimeters of mercury, with gastric pressure used as a zero reference; the values were obtained as the midrespiratory value. The results were expressed as a percentage of change in the sphincter pressure for the sphincter relaxation, and as absolute values for the excitatory motor responses. The percentage by which LES pressure decreased during swallowing was calculated as resting LES pressure minus the nadir of LES pressure during swallowing, divided by resting LES pressure times 100 . The stomach was intermittently aspirated to prevent gastric distension.

After recording the basal LES pressure, the right or left cervical sympathetic trunk was sectioned at a site $1.0 \mathrm{~cm}$ proximal to the superior cervical ganglion. LES pressure was continuously recorded during all procedures. After $30 \mathrm{~min}$, the other cervical sympathetic trunk was sectioned. A similar procedure was used for the splanchnic nerve studies. The greater splanchnic nerves were sectioned at a site $1.0 \mathrm{~cm}$ proximal to the celiac ganglion.

Electrical stimulation of the cervical sympathetic trunk, the cervical vagi, or the greater splanchnic nerves, was performed with a platinum wire bipolar electrode $(0.04 \mathrm{~mm}$ diameter $)$ which was mounted in polyvinyl tubing $(11.0 \mathrm{~mm}$ length, $5.0 \mathrm{~mm}$ diameter) and was sealed with bonded adhesive. The distance between stimulating points was $5.0 \mathrm{~mm}$. The distal or proximal ends of the nerves were placed into the trough-shaped electrode, covered with cotton, and saturated with mineral oil. Care was taken to prevent current leakage by elevating the nerve from adjacent tissues with cotton pledgets. An electrical stimulus was delivered with a Grass stimulator (Model 88, with stimulus isolation unit SIU 5, Grass Instrument Co., Quincy, Mass.). Square wave pulses of 1.0-ms stimulus duration, were delivered at a frequency range of $0.50-50 \mathrm{~Hz}$ and a voltage range of 5 or $10 \mathrm{~V}$. The length of the stimulus train was $5 \mathrm{~s}$. The trains were separated by intervals of at least $5 \mathrm{~min}$. A special procedure was carried out for the simultaneous stimulation of the cervical vagal trunk and the sympathetic nerves. The length of the stimulus train was $15 \mathrm{~s}$, either for the cervical sympathetic trunk or the greater splanchnic nerves; simultaneous vagal stimulation was performed $10 \mathrm{~s}$ after the onset of sympathetic stimulation. Responses to vagal or splanchnic nerve stimulation began with the onset of nerve stimulation and persisted for the duration of stimulation, returning to basal values upon the termination of the stimulus.

Drugs were administered through an intravenous catheter into the femoral vein. The agents were given as single intravenous boluses over $60 \mathrm{~s}$ or by continuous infusion. Normal saline was used to flush the catheter after each drug administration. The LES response to splanchnic nerve stimulation was measured in the same animals before and after administration of the different antagonists. A period of $60 \mathrm{~min}$ for stabilization to base-line levels was observed after the administration of each pharmacological agent. $1.5 \mathrm{mg} / \mathrm{kg}$ phentolamine (Regitine, CIBA-Geigy Corporation, Summit, N. J.) was chosen as the dose that antagonized the maximal LES response to phenylephrine at $24.0 \mu \mathrm{g} / \mathrm{kg}$. $1.0 \mathrm{mg} / \mathrm{kg}$ propranolol (Inderal, Ayerst Laboratories, New York) was given as the dose that antagonized the maximal LES response to $40 \mu \mathrm{g} / \mathrm{kg}$ isoproterenol. $30.0 \mu \mathrm{g} / \mathrm{kg}$ atropine sulfate (The Vitarine Co., Inc., New York) was selected as the dosage that antagonized completely the maximal LES response to $5.0 \mathrm{mg}$ bethanechol. Additional studies with 10.0 and $100.0 \mu \mathrm{g} / \mathrm{kg}$ atropine were performed. Trimethaphan camsylate (Arfonad, Roche Laboratories, Div. Hoffmann-LaRoche Inc., Nutley, N. J.), $4.0 \mathrm{mg} / \mathrm{min}$, was given at a dosage that inhibited the maximal blood pres- 
sure response during splanchnic nerve stimulation or the LES response to nicotine sulfate $(50.0 \mu \mathrm{g} / \mathrm{kg}) .5 .0-10.0 \mathrm{mg} / \mathrm{kg}$ guanethidine (Ismelin, CIBA-Geigy Corporation) was given at dosages previously reported to be effective in lowering blood pressure and blocking adrenergic neural function. Guanethidine effect was evaluated at 10-60 min after its adminstration. Alone, guanethidine gave significant reduction in blood pressure in all animals.

To eliminate the effect of preganglionic splanchnic nerve stimulation upon the adrenal glands, a group of animals were also studied after bilateral adrenalectomy.

Statistical analysis was performed with the paired $t$ test for observations made in a minimum of seven animals. All records were read in a blinded fashion without knowledge of the nerve stimulation or of the drug being employed.

\section{RESULTS}

Basal LES pressure in response to cervical or greater splanchnic nerve section. Cervical sympathetic section (unilateral or bilateral) at a site proximal to the cervical ganglion failed to significantly alter LES pressure. Greater splanchnic nerve section (unilateral or bilateral) at a site proximal to the celiac ganglion also did not significantly change the basal LES pressure. The control LES pressure was $15.66 \pm 1.41 \mathrm{~mm} \mathrm{Hg}$ (mean $\pm \mathrm{SEM}$ ) as compared with $16.02 \pm 1.28 \mathrm{~mm} \mathrm{Hg}$ after bilateral cervical sympathectomy $(P>0.05)$ and $18.00 \pm 2.10 \mathrm{~mm} \mathrm{Hg}$ after bilateral splanchnic nerve section $(P>0.05)$. LES pressures were similar with either pentobarbital or ketamine.

Cervical vagotomy (unilateral or bilateral) also failed to alter the basal LES tone. The LES pressure in control animals was $15.54 \pm 2.06 \mathrm{~mm} \mathrm{Hg}$ as compared with $15.37 \pm 2.15 \mathrm{~mm} \mathrm{Hg}$ after unilateral cervical vagotomy $(P>0.05)$, and $15.64 \pm 2.31 \mathrm{~mm} \mathrm{Hg}$ after bilateral cervical vagotomy $(P \pm 0.05)$. The basal LES pressure was also obtained in animals undergoing bilateral cervical vagotomy with either unilateral or bilateral cervical sympathetic or greater splanchnic nerve sectioning. Vagotomy plus sympathectomy also did not lead to significant alterations in basal LES tone $(P>0.05)$.

Effect of peripheral cervical sympathetic nerve stimulation on LES pressure, vagal-induced LES relaxation and blood pressure. Fig. 1 shows the percent decrease in LES pressure (above) and the change in mean blood pressure in $\mathrm{mm} \mathrm{Hg}$ (below) for a full frequency range at $5 \mathrm{~V}$ (left) and $10 \mathrm{~V}$ (right). Cervical sympathetic nerve stimulation did not alter LES pressure at either 5 or $10 \mathrm{~V}$ over the entire frequency range. Cervical sympathetic nerve stimulation did give a small increase in mean arterial blood pressure. Cervical vagal stimulation gave a decrease in LES pressure and mean blood pressure. Simultaneous stimulation of the cervical vagus and cervical sympathetic trunks did not alter either the percentage decrease in LES pressure or the mean decrease in arterial blood pressure at either voltage over the full frequency range.

Effect of stimulation of the central portion of the
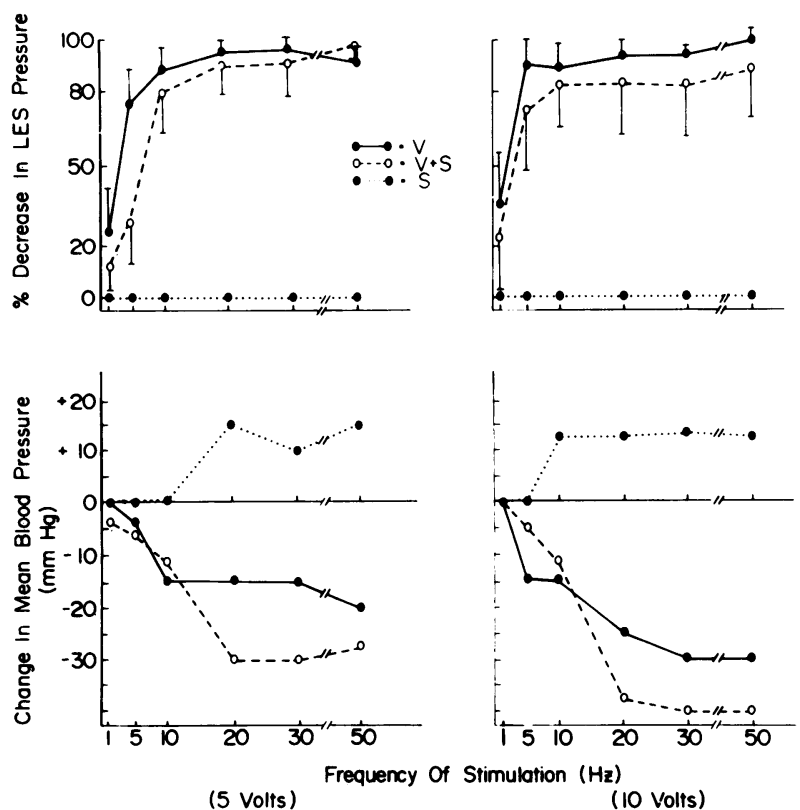

FIGURE 1 Effect of electrical stimulation of the distal end of the sectioned cervical sympathetic trunks on LES pressure (above), and on mean blood pressure (below). Sympathetic stimulation(s) produced no effect on sphincter pressure over the entire frequency range at 5 and $10 \mathrm{~V}$; it induced a slight increase in mean blood pressure. Peripheral vagal stimulation (V) induced a frequency-related sphincter relaxation and a decrease in blood pressure. Simultaneous stimulation of the sympathetic nerve $(\mathrm{V}+\mathrm{S})$ did not modify sphincter relaxation and blood pressure responses as induced by vagal stimulation.

cervical sympathetic or splanchnic nerves on LES pressure; action of antagonist agents. Fig. 2 shows the effect of electrical stimulation of the central end of the cut cervical sympathetic or greater splanchnic nerves. Data is expressed as a percent decrease in LES

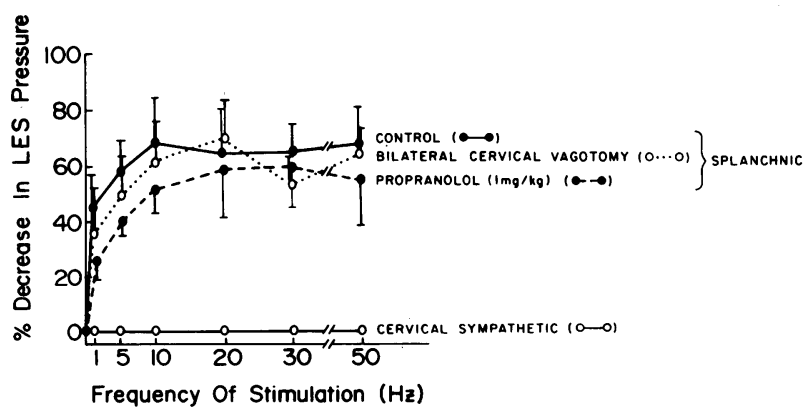

FIGURE 2 Effect of electrical stimulation of the central end of the sectioned cervical sympathetic or splanchnic nerve on LES pressure. Electrical stimulation at $10 \mathrm{~V}$ was applied over an entire frequency range. Stimulation of the central end of the cut cervical sympathetic nerve gave no change in sphincter pressure. Stimulation of the central end of the cut splanchnic nerve produced a decrease in sphincter pressure. Bilateral cervical vagotomy or propranolol did not modify this response. 
pressure at $10 \mathrm{~V}$ over the full frequency range. Central cervical sympathetic nerve stimulation did not alter LES pressure at any point. Stimulation of the central portion of the greater splanchnic nerve gave a decrease in LES pressure; maximum inhibition of $69.1 \pm 16.0 \%$ was noted at a frequency of $10 \mathrm{~Hz}$.

The inhibition in LES pressure noted during central stimulation of the cut splanchnic nerve was next studied during bilateral cervical vagotomy, or after the administration of propranolol ( $1.0 \mathrm{mg} / \mathrm{kg}$, i.v.). This dose of propranolol was selected as the lowest dose which produced complete antagonism of the maximum inhibitory effect of isoproterenol $(4.0 \mu \mathrm{g} / \mathrm{kg}$, i.v.) on LES pressure. Change in LES pressure was similar at all frequencies $(P>0.05)$ after either vagotomy or propranolol.

In additional studies, not shown here, it was demonstrated that bilateral cervical sympathectomy or cutting of the contralateral splanchnic nerve also failed to alter the response to central splanchnic nerve stimulation.

Effect of stimulation of the peripheral portion of the splanchnic nerve on LES pressure. Fig. 3A shows the effect of electrical stimulation of the peripheral end of the greater splanchnic nerve at 5,7 , and $10 \mathrm{~V}$ over a full frequency range. Peripheral splanchnic nerve stimulation gave an increase in LES pressure. These changes in LES pressure were voltage and frequency dependent. The LES pressure changes at $5 \mathrm{~V}$ were not statistically significant. The LES pressure changes at $7 \mathrm{~V}$ were significant at frequencies of 10 and $20 \mathrm{~Hz}$. At $10 \mathrm{~V}$, the LES pressure changes were significant at $5,10,20$, and $30 \mathrm{~Hz}$. These changes in LES pressure were observed with both intact and cut vagal trunks.

Fig. 3B shows the time course of the LES response to right splanchnic nerve stimulation of 15- or 5-s duration. LES pressure rises rapidly but falls slowly after termination of the stimulus.

Effect of ganglionic blockade upon the excitatory effect of peripheral splanchnic nerve stimulation on LES pressure. Fig. 4 shows the effect of ganglionic blockade with trimethaphan camsylate $(4.0 \mathrm{mg} / \mathrm{min}$, i.v.) upon LES pressure and mean arterial blood pressure during stimulation of the peripheral end of the greater splanchnic nerve. Trimethaphan camsylate was selected at a dosage that would antagonize the increase in blood pressure during splanchnic nerve stimulation. Trimethaphan camsylate completely antagonized the increase in LES pressure over the entire frequency range of direct peripheral splanchnic nerve stimulation.

Effect of guanethidine and bilateral adrenalectomy upon the excitatory effect of peripheral splanchnic nerve stimulation on LES pressure and blood pressure. Fig. 5 shows the effect of stimulation of the peripheral end of the splanchnic nerve in the presence of guanethidine $(5.0$ or $10.0 \mathrm{mg} / \mathrm{kg}$, i.v.) alone, and guanethidine

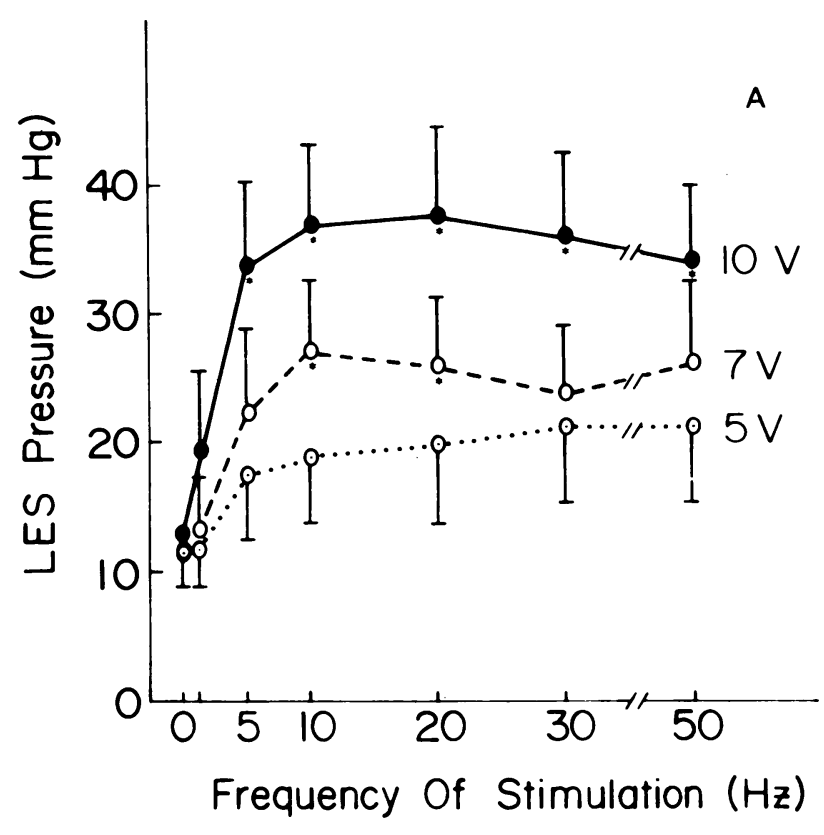

B

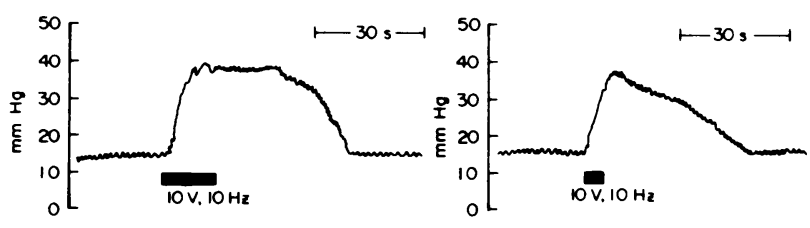

FIgURE 3 (A) Effect of electrical stimulation of the peripheral end of the cut greater splanchnic nerve at 5,7 , and $10 \mathrm{~V}$ over a frequency range of $1-50 \mathrm{~Hz}$. Electrical stimulation produced an increase in LES pressure. The change in LES pressure was significant at 7 and $10 \mathrm{~V}$ (indicated by an asterisk). (B) Time course of LES response to right splanchnic nerve stimulation at $10 \mathrm{~V}, 10 \mathrm{~Hz}$ for a stimulus train at $15 \mathrm{~s}$ (left) and $5 \mathrm{~s}$ (right). Pressure rose rapidly, but fell slowly upon termination of the stimulus.

plus bilateral adrenalectomy. Alone, guanethidine significantly augmented the excitatory effect of stimulation of the peripheral end of the splanchnic nerve at frequencies of $5,10,20,30$, and $50 \mathrm{~Hz}$ on LES pressure. Guanethidine alone also gave a slight augmentation of the increase in mean arterial blood pressure. These changes in blood pressure were not significant. Because guanethidine does not alter adrenal medullary activity during splanchnic nerve stimulation, animals were further studied after bilateral adrenalectomy. After bilateral adrenalectomy, guanethidine continued to augment the LES pressure response to peripheral splanchnic nerve stimulation. The increase in LES pressure was slightly higher than seen with guanethidine alone, but this difference was not significant. Bilateral adrenalectomy. in combination with 

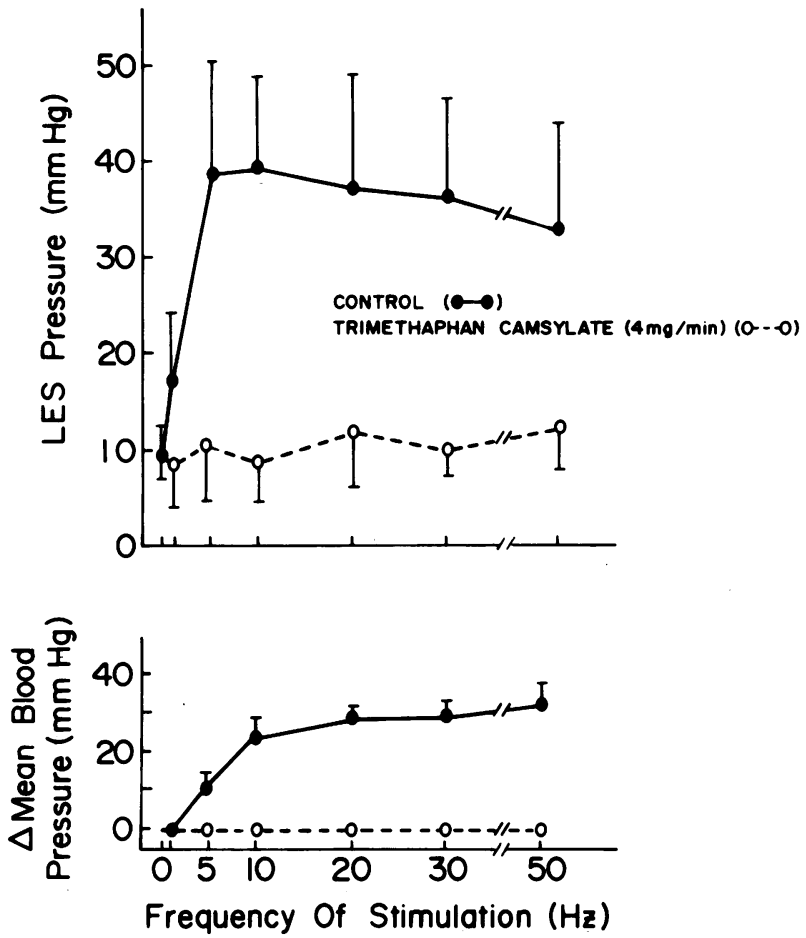

FIGURE 4 Effect of trimethaphan camsylate on the frequency response curve of peripheral splanchnic nerve stimulation upon LES pressure (above), and mean blood pressure (below), at $10 \mathrm{~V}$. Trimethaphan camsylate completely suppressed the excitatory effect on both the sphincteric and blood pressure responses.
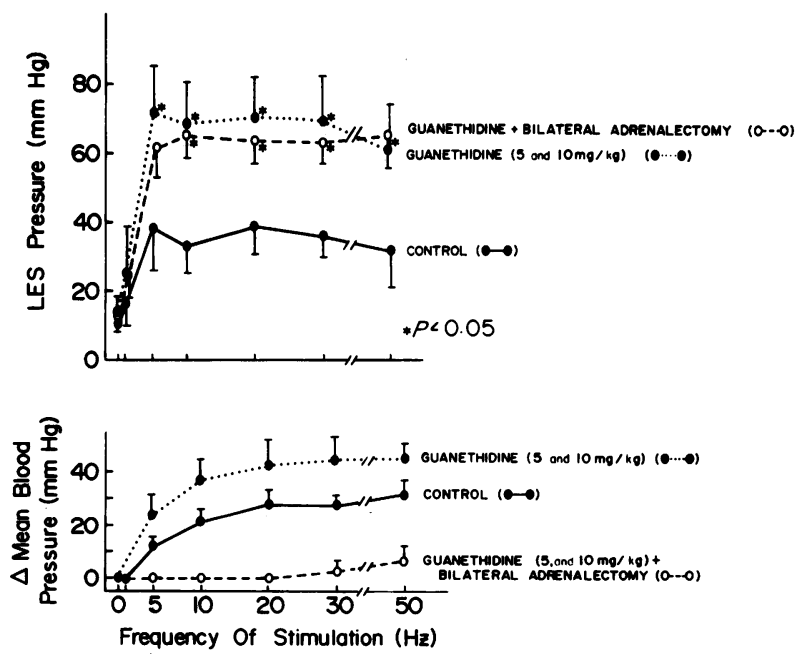

FIGURE 5 Effect of guanethidine on the frequency response curve of peripheral splanchnic nerve stimulation upon LES pressure (above), and mean blood pressure (below), at $10 \mathrm{~V}$. Guanethidine ( 5 and $10 \mathrm{mg} / \mathrm{kg}$ ) increased the excitatory effect of splanchnic nerve stimulation on LES and blood pressure. Guanethidine (5 and $10 \mathrm{mg} / \mathrm{kg}$ ) plus bilateral adrenalectomy abolished the change in blood pressure, but continued to augment the LES pressure response to peripheral splanchnic nerve stimulation. guanethidine completely abolished the changes in mean blood pressure during peripheral splanchnic nerve stimulation. Adrenalectomy alone reduced the blood pressure but not the LES response to splanchnic stimulation.

These observations suggested that the inhibition of catecholamine release by guanethidine augmented the increase in LES pressure during peripheral splanchnic nerve stimulation. These changes in LES pressure could be dissociated from the alterations in blood pressure noted during nerve stimulation.

Effect of alpha adrenergic antagonism with phentolamine upon the excitatory effect of peripheral splanchnic nerve stimulation on LES pressure and mean blood pressure. Fig. 6 shows the effect of phentolamine (1.5 $\mathrm{mg} / \mathrm{kg}$, i.v.) upon the excitatory effect of peripheral splanchnic nerve stimulation on LES pressure and mean blood pressure. Phentolamine was selected at the lowest dosage that would completely antagonize the maximal excitatory action of phenylephrine (24.0 $\mu \mathrm{g} / \mathrm{kg}, \mathrm{i} . v$.) on the LES. Phentolamine augmented the effect on the LES response to peripheral splanchnic nerve stimulation at $10 \mathrm{~V}, 1 \mathrm{~Hz}$. There was no effect at other stimulus parameters. Phentolamine did completely antagonize the increase in mean blood pressure noted during splanchnic nerve stimulation.

Thus, alpha adrenergic antagonism with phentolamine, at a dosage sufficient to block the maximal excitatory action of phenylephrine on the LES and the
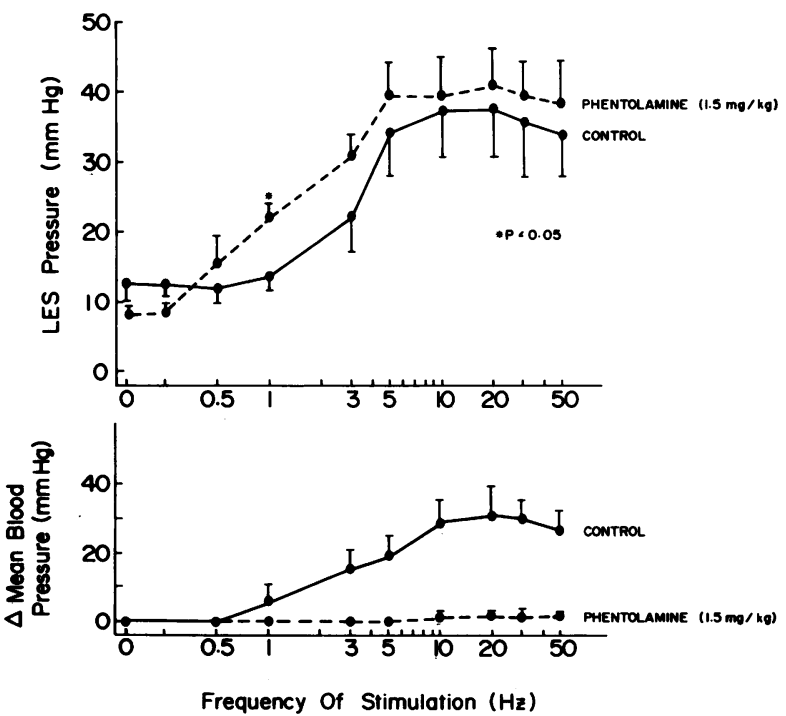

FIGURE 6 Effect of phentolamine on the frequency response curve of peripheral splanchnic nerve stimulation upon LES pressure (above), and mean blood pressure (below), at $10 \mathrm{~V}$. Phentolamine increased the LES pressure response to peripheral splanchnic nerve stimulation at $1 \mathrm{~Hz}$, but had no significant effect at the other frequencies. Phentolamine did completely antagonize the increase in mean blood pressure noted during splanchnic nerve stimulation. 
effect of splanchnic nerve stimulation on blood pressure, failed to alter the excitatory action of nerve stimulation on LES pressure.

Effect of combined alpha and beta adrenergic antagonism upon the excitatory effect of peripheral splanchnic nerve stimulation on LES pressure. Fig. 7 shows the effect of propranolol (1.0 mg/kg, i.v.) alone, and propranolol plus phentolamine upon the excitatory effect of peripheral splanchnic nerve stimulation. Neither propranolol alone, nor propranolol plus phentolamine significantly altered the LES response to splanchnic nerve stimulation. Blood pressure responses were inhibited during propranolol and phentolamine administration, but not with propranolol alone.

Effect of atropine sulfate upon the excitatory effect of peripheral splanchnic nerve stimulation on LES pressure and mean blood pressure. Fig. 8 shows the effect of intravenous atropine sulfate at doses of 10 , 30 , and $100 \mu \mathrm{g} / \mathrm{kg}$ upon the LES pressure and blood pressure responses to peripheral splanchnic nerve stimulation. Each dose of atropine reduced the LES pressure response to splanchnic nerve stimulation. The changes in response to atropine at $10 \mu \mathrm{g} / \mathrm{kg}$ were not significant. Both higher doses of atropine, 30 and 100

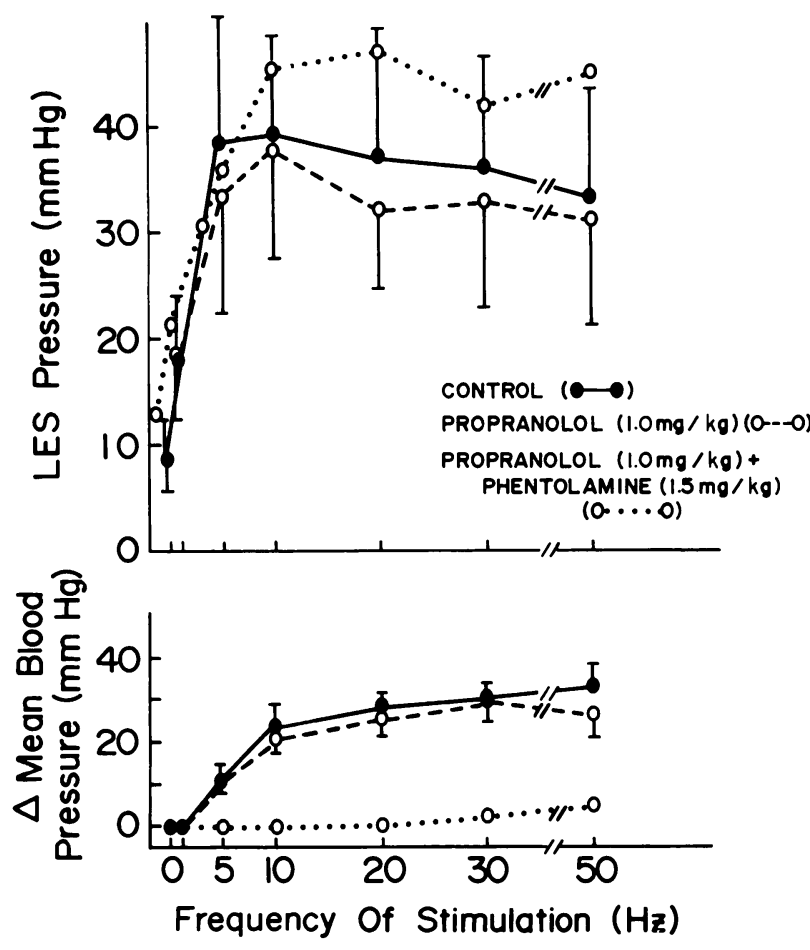

FIGURE 7 Effect of propranolol on the frequency response curve of peripheral splanchnic nerve stimulation on LES pressure (above), and mean blood pressure (below), at $10 \mathrm{~V}$. Propranolol did not change the sphincter pressure or blood pressure responses to splanchnic nerve stimulation. The combination of the adrenergic antagonists, phentolamine and propranolol, was also ineffective.
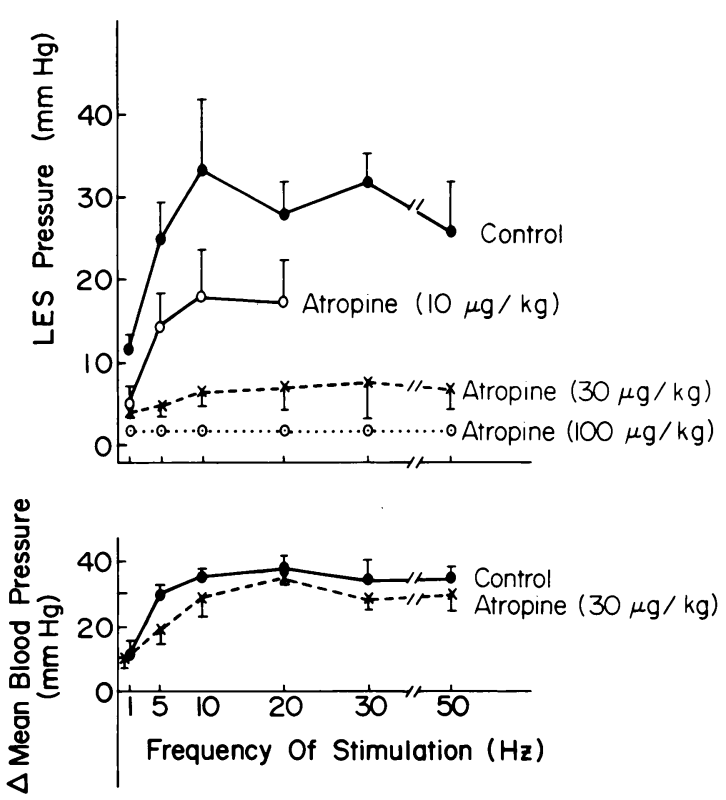

FIGURE 8 Effect of atropine sulfate on the frequency response curve of peripheral splanchnic nerve stimulation on LES pressure (above), and mean blood pressure (below), at $10 \mathrm{~V}$. At a dose of $10.0 \mu \mathrm{g} / \mathrm{kg}$, atropine did not significantly decrease the sphincter pressure response to splanchnic nerve stimulation. At a dose of $30.0 \mu \mathrm{g} / \mathrm{kg}$, atropine significantly decreased this response. A dose of $100.0 \mu \mathrm{g} / \mathrm{kg}$ atropine completely suppressed the sphincteric response for several hours. No significant change in blood pressure responses was noted at each dose of atropine.

$\mu \mathrm{g} / \mathrm{kg}$, significantly reduced or abolished the increase in LES pressure during splanchnic nerve stimulation. The complete antagonism of the LES response during atropine at $100 \mu \mathrm{g} / \mathrm{kg}$ lasted for several hours. At all doses atropine failed to significantly alter the increase in mean blood pressure during splanchnic nerve stimulation. Identical effects of atropine on the LES response to splanchnic stimulation were observed with intact or cut vagi.

Effect of peripheral splanchnic nerve stimulation upon LES relaxation as induced by vagal stimulation. Fig. 9 shows the effect of peripheral splanchnic nerve stimulation upon LES relaxation as induced by vagal stimulation. Results are shown for vagal stimulation at $10 \mathrm{~V}$ over a full frequency range. Splanchnic stimulation was tested at $10 \mathrm{~V}, 20 \mathrm{~Hz}$ (left) and $10 \mathrm{~V}, 10 \mathrm{~Hz}$ (right). Splanchnic stimulation at either frequency significantly reduced submaximal and maximal inhibitory responses to vagal stimulation. These results should be contrasted with the findings in Fig. 1, where cervical sympathetic stimulation was shown to have no effect on LES relaxation as induced by vagal stimulation.

Effect of atropine on the action of peripheral splanchnic stimulation on LES relaxation as induced 


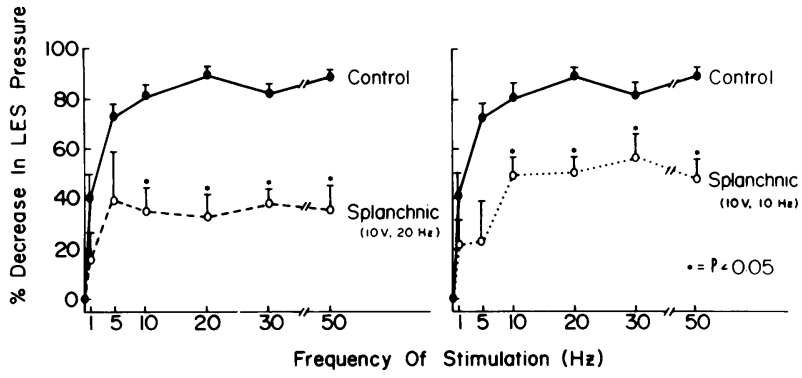

FIGURE 9 Effect of peripheral splanchnic nerve stimulation during LES relaxation as induced by vagal stimulation. Electrical vagal stimulation at $10 \mathrm{~V}$ induced LES pressure relaxation. Simultaneous stimulation of the peripheral end of the splanchnic nerve at the parameters of stimulation of maximal effect on the sphincter $(10 \mathrm{~V}, 10 \mathrm{~Hz}$ or $10 \mathrm{~V}, 20 \mathrm{~Hz})$ significantly decreased the submaximal and maximal inhibitory sphincteric responses to vagal stimulation.

by vagal stimulation. Fig. 10 shows the effect of atropine sulfate on splanchnic stimulation during LES relaxation as induced by vagal stimulation. Atropine sulfate was given at the dosage ( $30 \mu \mathrm{g} / \mathrm{kg}$, i.v.) shown to antagonize the excitatory effect of splanchnic nerve stimulation on LES pressure (Fig. 8). Atropine completely antagonized the inhibitory effect of splanchnic nerve stimulation upon LES relaxation. After atropine, LES relaxation was similar to control values at each frequency.

\section{DISCUSSION}

The results of these studies suggest several points. First, the cervical sympathetic nerves proximal to the

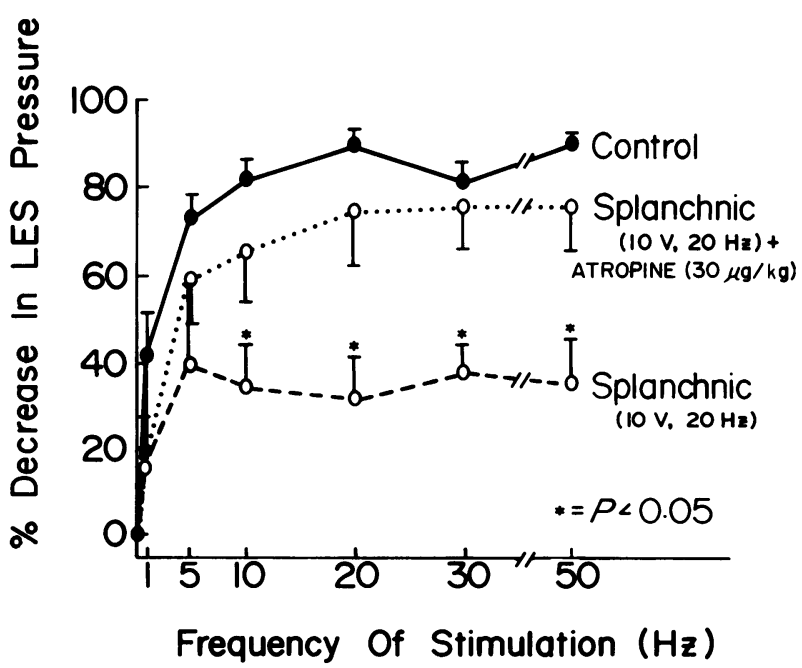

Figure 10 Effect of atropine sulfate on splanchnic stimulation during LES relaxation as induced by vagal stimulation. Atropine $(30.0 \mu \mathrm{g} / \mathrm{kg}$ ) abolished the antagonistic effect of splanchnic nerve stimulation $(10 \mathrm{~V}, 20 \mathrm{~Hz})$ upon LES pressure relaxation during vagal stimulation. cervical ganglion have no effect on LES pressure when stimulated centrally or peripherally. Second, the central portion of the greater splanchnic nerve has an inhibitory effect on LES pressure that acts independently of the beta adrenergic receptor or central vagal pathways. Third, the peripheral portion of the greater splanchnic nerve has an excitatory effect on LES pressure that is mediated through a ganglionic synapse (possibly celiac ganglion), and is sensitive to atropine but not to alpha or beta adrenergic antagonism. Fourth, inhibition of catecholamine release by guanethidine augments the atropine-sensitive, excitatory effect of splanchnic nerve stimulation on LES pressure. Fifth, the independent effects of sympathetic nerve stimulation on LES pressure and blood pressure can be dissociated with specific antagonist agents. Sixth, bilateral cervical sympathetic or greater splanchnic nerve sectioning has little effect on the basal LES pressure.

The role of the sympathetic neural innervation to the LES has been difficult to ascertain. Most previous studies used specific agonists or antagonists to ascertain the function of the alpha or beta adrenergic receptors. In the esophagus of the opossum, the cat, and man, the alpha adrenergic receptor mediates an excitatory effect, whereas the beta adrenergic receptor produces an inhibitory response $(6,7)$. Direct antagonism of alpha adrenergic activity gives a small decrease in basal LES pressure. Beta adrenergic antagonists have no apparent effect on basal sphincter tone (7). Destruction of the adrenergic nerves with 6-hydroxydopamine leads to hypersensitivity to exogenous adrenergic agents, but gives only a small decrease in basal LES pressure without affecting LES relaxation in response to swallowing (7). Based on studies of this type, suggestions have been made concerning the role of the actual sympathetic nerves in regulating LES pressure and LES relaxation. This study indicates that observations based upon exogenous agonist administration may bear little relationship to the actual function of the nerves themselves, when stimulated or sectioned. A similar phenomenon was recently described for the vagal innervation to the LES. It was suggested that the major vagal neurotransmitter was acetylcholine and that the vagus carried excitatory cholinergic fiber to the LES (5). However, when the vagi were cut in the neck, LES pressure was not reduced (10). Furthermore, direct vagal stimulation led to a nonadrenergic, noncholinergic (puringergic) relaxation in LES tone $(3,11)$. The absence of excitatory cholinergic innervation to the LES within the vagus has led to certain doubts that the LES received any direct excitatory cholinergic innervation (3). The reduction in LES pressure with atropine in certain animals and in man was unexplained $(4,12)$.

This study suggests that the greater splanchnic nerve carries an excitatory atropine-sensitive response to the LES. This conclusion is based upon the observation 
that atropine sulfate; but not phentolamine, propranolol, or guanethidine; antagonizes the increase in LES pressure during the peripheral splanchnic nerve stimulation. It is uncertain whether the action of atropine is upon the muscarinic receptor in the muscle membrane, or whether atropine acts at the ganglion. It is most likely that the action of atropine is at the muscle membrane.

Even at small doses, atropine suppressed the effect of splanchnic nerve stimulation for several hours. At those doses, atropine is a highly selective antagonist of muscarinic agents on smooth muscle (13). The action of small doses of atropine makes the other possible action of this drug less tenable. Under appropriate experimental conditions and in high dose, atropine is known to have an alpha sympatholytic effect (14). Likewise, atropine in high doses may antagonize the nicotinic action of acetylcholine at the autonomic ganglion (13). On the other hand, muscarinic antagonism at a ganglionic synapse does not usually abolish a response as observed in these studies. It should be emphasized that ganglionic blockade with trimethaphan camsylate abolished the LES response to splanchnic stimulation, but this drug also antagonized the increase in blood pressure as well. Atropine reduced the LES response without altering blood pressure.

Cholinergic pathways in the sympathetic nerves have been described in other studies with different end organ responses (15-20). However, this is the initial demonstration of an excitatory cholinergic response obtained during sympathetic nerve stimulation. Usually, mixed, cholinergic, and adrenergic responses are described $(18,20)$. The neural pathway of this cholinergic response is not clear; the simplest explanations would be the existence of cholinergic fibers within the splanchnic nerve, or some connection with the parasympathetic nerves $(15,18)$. The excitatory action of splanchnic nerve stimulation on the LES was specific for this nerve and was not observed during cervical sympathetic nerve stimulation.

Guanethidine in the presence or absence of the adrenal glands augmented the LES pressure response to splanchnic nerve stimulation. This response was independent of the drug's effect on blood pressure. The action of guanethidine in augmenting the excitatory action of peripheral splanchnic nerve stimulation was unexpected. Guanethidine is known to cause adrenergic neuroblockade, noradrenaline potentiation, and sympathomimetic effects by release of noradrenaline $(21,22)$. Noradrenaline potentiation seems to be unrelated to its action on adrenergic nerves (23). The increase in the sensitivity of tissues to circulating catecholamines was suggested by the increased response in blood pressure during splanchnic nerve stimulation. This response was suppressed after bilateral adrenalectomy. Guanethidine has no effect on the release of catecholamines from the adrenal medulla (24). Adrenalectomy did not modify the LES response to guanethidine during splanchnic nerve stimulation, thus suggesting that the effect on the LES was not a result of potentiation of the action of released catecholamines. A possible sympathomimetic effect of guanethidine seems unlikely as no change in resting LES pressure was noted after drug injection. The action of guanethidine does not seem to be related to noradrenaline potentiation or a sympathomimetic effect, as its effects were not modified by an alpha blocking agent, phentolamine. It is possible that guanethidine augmented the LES response to splanchnic stimulation by the blockage of a simultaneous inhibitory adrenergic response elicited during splanchnic stimulation (25-27). However, the demonstration that effective alpha, but not beta, blockage only minimally augments the excitatory response to splanchnic nerve stimulation makes this possible explanation less tenable. Therefore, the mechanism by which guanethidine augmented the LES response to splanchnic nerve stimulation remains undefined.

The splanchnic nerves, when stimulated at the peripheral end, also seemed capable of inhibiting LES relaxation in response to direct vagal stimulation. This inhibitory response was not seen during cervical sympathetic nerve stimulation. The physiological role of the splanchnic nerves in altering the LES response to vagal stimulation is unclear. This study does not define the significance of this response in health or in disease, but simply indicates the presence of a neural pathway within the splanchnic nerves that can limit the ability of the vagi to induce LES relaxation. This splanchnic response was sensitive to atropine but not to the other neural antagonists. A similar reduction in LES relaxation as induced by vagal stimulation has been shown during intravenous dopamine infusion and during subcutaneous addition of bethanechol $(28,29)$. The present study suggests that the magnitude of LES relaxation may be reduced by splanchnic nerve stimulation as well as by certain drugs.

Stimulation of the central end of the splanchnic nerve gave a decrease in LES pressure. This response was unchanged after bilateral cervical sympathetic or bilateral vagal sectioning in the neck. Additionally, direct stimulation of the cervical sympathetic nerve also failed to elicit this response. The central splanchnic response was not antagonized by a seemingly effective dose of a beta adrenergic antagonist, propranolol. Also, section of the contralateral splanchnic nerve failed to abolish this inhibitory response. These results would suggest that the inhibitory response was transmitted by a nonadrenergic neurotransmitter that is carried to the LES through unknown pathways. It is possible that the central portion of the splanchnic nerve connects with inhibitory pathways in the vagus nerves within the thorax. 
This may occur without connection to the brain stem. It has been shown that many small branches of the vagus within the chest can initiate LES relaxation when stimulated directly (30).

In summary, this study emphasizes several important points concerning the sympathetic innervation of the LES. First, studies during direct neural stimulation may give results quite different than would be predicted from studies using the exogenous administration of agonist or antagonist compounds. Second, the LES does have an atropine-sensitive excitatory innervation that is carried in the greater splanchnic nerve. Third, the sympathetic innervation may modulate the action of direct vagal inhibition on the LES. Fourth, although adrenergic inhibition with guanethidine augments the excitatory, atropine-sensitive increase in LES pressure during splanchnic nerve stimulation, the true intrinsic role of the alpha and beta adrenergic receptors in the regulation of LES function remains unclear.

\section{ACKNOWLEDGMENTS}

The authors wish to thank Ms. Mary Carroll for secretarial assistance.

This work was supported by Research grant R01 AM19379 from the National Institutes of Health.

\section{REFERENCES}

1. Rattan, S., and R. K. Goyal. 1974. Neural control of the lower esophageal sphincter. Influence of the vagus nerves. J. Clin. Invest. 54: 889-906.

2. Matarazzo, S. A., W. J. Snape, Jr., J. P. Ryan, and S. Cohen. 1976. Relationship of cervical and abdominal vagal activity to lower esophageal sphincter function. Gastroenterology. 71: 999-1003.

3. Goyal, R. K., and S. Rattan. 1975. Nature of the vagal inhibitory innervation to the lower esophageal sphincter. J. Clin. Invest. 55: 1119-1126.

4. Gonella, J., J. P. Niel, and C. Roman. 1977. Vagal control of lower esophageal sphincter motility in the cat. J. Physiol. (Lond.). 273: 647-664.

5. Christensen, J. 1968. Pharmacology of the esophagus. Handb. Physiol. 4(Sect. 6): 2325-2330.

6. Christensen, J., and E. E. Daniel. 1968. Effects of some autonomic drugs on circular esophageal smooth muscle. J. Pharmacol. Exp. Ther. 159: 243-247.

7. DiMarino, A. J., and S. Cohen. 1973. The adrenergic control of lower esophageal sphincter function.J. Clin. Invest. 52: 2264-2271.

8. Carlson, A. J., T. E. Boyd, and J. F. Pearcy. 1922. The innervation of the cardia and the lower end of the esophagus in mammals. Am. J. Physiol. 61: 14-41.

9. Ingelfinger, F. J. 1958. Esophageal motility. Physiol. Rev. 38: 533-584.

10. Ryan, J. P., W. J. Snape, Jr., and S. Cohen. 1977. Effect of vagal cooling on esophageal peristalsis and sphincter relaxation. Am J. Physiol. 1: E159-E165.

11. Tuch, A., and S. Cohen. 1973. Lower esophageal sphincter relaxation: studies on the neurogenic inhibitory mechanism. J. Clin. Invest. 52: 14-20.
12. Lind, J. F., J. S. Crispin, and D. K. McIver. 1968. The effect of atropine on the gastroesophageal sphincter. Can. J. Physiol. Pharmacol. 46: 233-238.

13. Goodman, L. S., and A. Gilman, editors. 1970. Drugs inhibiting the action of acetylcholine on structure innervated by postganglionic parasympathetic nerves. In The Pharmacological Basis of Therapeutics 1970. Macmillan \& Co. Ltd., London. 521.

14. Ludvena, F. B., and M. J. Branin. 1966. Adrenolytic activity of atropine $(+)$ hyoscyamine, atroscine, homatropine and related compounds. J. Pharm. Sci. 55: 280-284.

15. Kure, K., and M. Fujii. 1933. Influence of spinal parasympathetic on blood vessels and external secretion of pancreas. Q. J. Exp. Physiol. Cogn. Med. Sci. 22: $323-328$.

16. Kure, K., K. Kanda, A. Wakabayaski, and S. Okinaka. 1933. Parasympathetic nerve supply of the kidney. Q. J. Exp. Physiol. Cogn. Med. Sci. 22: 315-321.

17. Dale, H. H., and W. Feldberg. 1934. The chemical transmission of secretory impulses to the sweat glands of the (at. J. Physiol. (Lond.). 82: 121-128.

18. Gillespie, J. S., and B. R. MacKenna. 1961. The inhibitory action of the sympathetic nerves on the smooth muscle of the rabbit gut, its reversal by reserpine and restoration by catecholamines and by dopa. J. Physiol. (Lond.). 156: $17-34$.

19. Barlow, T. E., J. R. Greenwell, A. A. Harper, and T. Scratchers. 1974. The influence of the splanchnic nerves on the external secretion, blood flow and electrical conductance of the cat pancreas. J. Physiol. (Lond.). 236: 421-433.

20. Persson, C. G. A. 1973. Dual effects on the sphincter of Oddi and gallbladder induced by stimulation of the right great splanchnic nerve. Acta Physiol. Scand. 87: 334-343.

21. Goodman, L. S., and A. Gilman, editors. 1970. In The Pharmacologic Basis of Therapeutics 1970. Macmillan \& Co. Ltd., London. 570.

22. Forster, R. W., D. S. Shah, and R. C. Small. 1978. A study of the sympathomimetic action of guanethidine on the isolated anococcygeus muscle of the rat. Br.J. Pharmacol. 62: $307-313$.

23. Maxwell, R. A. 1965. Concerning the mode of action of guanethidine and some derivatives in augmenting the vasomotor action of adrenergic amines in vascular tissues of the rabbit. J. Pharmacol. Exp. Ther. 148: 32()-328.

24. Abercrombie, G. F., and B. N. Davies. 1963. The action of guanethidine with particular reference to the sympathetic nervous system. Br. J. Pharmacol. 20: 171-177.

25. Paton, W. D. M., and E. S. Vizi. 1969. The inhibitory action of noradrenaline and adrenaline on acetylcholine output by guinea pig ileum longitudinal muscle strip. Br. J. Pharmacol. 35: 10-28.

26. De Groat, W. C., and W. R. Saum. 1972. Sympathetic inhibition of the urinary bladder and of pelvic ganglionic transmission in the cat. J. Physiol. (Lond.). 220: 297-314.

27. Gillespie, J. S., and M. A. Khoyi. 1975. A pharmacological analysis of the inhibitory effects of the sympathetic nerves on the rabbit colon. J. Physiol. (Lond.). 244: 42p-43p.

28. Doody, P., S. Rattan, and R. K. Goyal. 1976. Adrenergic modulation of the vagal inhibitory action: evidence for dopamine receptors. Gastroenterology. 70: 139. (Abstr.)

29. Fournet, J., W. J. Snape, Jr., and S. Cohen. 1978. Modulation of lower esophageal sphincter relaxation. Clin. Res. 26: 318A. (Abstr.)

30. Kravitz, J. J., W. J. Snape, Jr., and S. Cohen. 1978. Effect of thoracic vagotomy and vagal stimulation on esophageal function. Am. J. Physiol. 234: E359-E364. 